\title{
1972 Network competition in a resin-modified glass-ionomer cement
}

A. YELAMANCHILI, and B.W. DARVELL, The University of Hong Kong, Victoria, Hong Kong

\begin{abstract}
Attempts have been made to improve the mechanical properties and convenience of use of glass-ionomer cement ( GIC) by various modifications, e.g. including a free-radical polymerizable component ("resin-modified" GIC, RMGIC). Necessarily, the one replaces part of the other, but the chemistry suggests that the formation of each network separately would inhibit diffusion and thus the other reaction. Objectives: To determine the variation in the $24-\mathrm{h}$ compressive strength of an RMGIC with irradiation regime. Methods: Cylindrical specimens ( $6 \mathrm{~mm} \times 3 \mathrm{~mm}$ diameter) of one brand of RMGIC (Shades A3, D2; Fuji II LC, GC; capsules) were prepared in ptfe moulds. After machine-mixing for $10 \mathrm{~s}, 3$ increments were irradiated from the top for various times ( 0 to $60 \mathrm{~s}$ : from the top only, top + bottom; top + bottom + side after ejection; with two lamps; at various delays after mixing ( 2 min to 18 h); 4 replicates of each. After exposure, or as appropriate, specimens were wrapped tightly in aluminium foil for storage dry in the dark at 37 ㅇ $\mathrm{C}$ for testing at $24 \mathrm{~h}$ after mixing. Specimens with evident defects were replaced before testing. Results: For toponly irradiation, strength rose from the unirradiated value (66 $\pm 9 \mathrm{MPa}$ ) to a peak at $20 \mathrm{~s}$ (manufacturer's

recommendation) $(215 \pm 25)$, after which it declined steadily. Adding bottom illumination gave a small decrease in peak value (194 \pm 36$)$; adding side illumination reduced it substantially (113 \pm 7 ). Delay for 2 min gave a marked reduction (155 \pm 15 ), declining to the unirradiated value at $18 \mathrm{~h}(70 \pm 15)$. No effect due to shade was detected. Conclusions: Competition between network-forming reactions leads to a sensitive balance between the two, and a critical optimum irradiation: too much may be detrimental, as is delay. The essential compromise involved in mixed chemistry jeopardizes reliability.
\end{abstract}

Seq \#161 - Keynote Address and New Materials and Improved Understanding of Dental Polymers 1:30 PM-3: 30 PM, Friday, 30 J une 2006 Brisbane Convention \& Exhibition Centre Plaza Terrace

Back to the Dental Materials: $V$ - Polymer Materials-Chemistry Program

Back to the IADR General Session \& Exhibition (June 28 - July 1, 2006) 